\title{
Development of a Decision-Aid Form (DAF) for the stratification of care in a French comprehensive cancer center, a tool to support identification of care goals
}

\author{
Laurence Vigouret-Viant ${ }^{1}$, Clémence Legoupil ${ }^{2}$, Aurélie Bardet ${ }^{2}$, Céline Laurent ${ }^{3}$, Michel Ducreux $^{4}$, \\ Sophie Laurent ${ }^{1}$, Christine Mateus ${ }^{1}$, Sarah Dauchy ${ }^{1}$, François Blot ${ }^{5} \wedge$ \\ ${ }^{1}$ Supportive Care Unit, Interdisciplinary Cancer Course Department, Gustave Roussy, Paris-Saclay University, Villejuif, France; ${ }^{2}$ Biostatistics and \\ Epidemiology Department, Gustave Roussy, Paris-Saclay University, Villejuif, France; ${ }^{3}$ Clinical Research Associate, Gustave Roussy, Paris-Saclay \\ University, Villejuif, France; ${ }^{4}$ Medical Oncology Department, Gustave Roussy, Paris-Saclay University, Villejuif, France; ${ }^{5}$ Intensive Care Unit, \\ Gustave Roussy, Paris-Saclay University, Villejuif, France \\ Contributions: (I) Conception and design: L Vigouret-Viant, C Mateus, S Dauchy, F Blot; (II) Administrative support: M Ducreux, S Dauchy; (III) \\ Provision of study materials or patients: L Vigouret-Viant, S Laurent, C Mateus, F Blot; (IV) Collection and assembly of data: A Bardet, C Laurent; \\ (V) Data analysis and interpretation: L Vigouret-Viant, C Legoupil, A Bardet, F Blot; (VI) Manuscript writing: All authors; (VII) Final approval of \\ manuscript: All authors. \\ Correspondence to: François Blot, MD. Intensive Care Unit, Gustave Roussy, Paris-Saclay University, 114, rue Edouard-Vaillant, 94800 Villejuif, \\ France. Email: francois.blot@gustaveroussy.fr.
}

Background For cancer patients, life-threatening complications may be difficult to anticipate, which can lead to complex medical decision-making processes. Since 2015, the Gustave Roussy Cancer Center has used a Decision-Aid Form (DAF), which contains an estimated gradation of care in cases where patients' conditions worsen. In this study, we assessed the acceptability of the DAF and the predictive value of the proposed stratification of care with regard to care delivered and patient's outcomes.

Methods: During a 5-month period, all patients who had been transferred from Site 1 to Site 2 of the hospital were prospectively included.

Results: A DAF was completed for $89.3 \%$ of the 206 patients included. Planned stratification of care was indicated in nearly all cases. The involvement of the palliative care team was indicated in only $29 \%$ of the DAF. The value of the WHO/ECOG Performance Status (PS) was limited. Finally, the field "information for patients and relatives" was infrequently completed. Although the possibility of transfer to the Intensive Care Unit was proposed for two-thirds of the patients, $76 \%$ of the 35 patients experiencing an acute event received only medical or palliative care. Overall, the level of therapeutic commitment suggested by the DAF was most often revised towards less aggressive care.

Conclusions: The results of our study suggest that implementing an advanced stratification record is possible in a French cultural setting. To achieve complete cultural acceptance, our large integrated institutional program continues to play a key role in anticipating intent, tracing and sharing information with patients and their relatives.

Keywords: Palliative care; aggressiveness of care; cancer; prognosis; advance care planning (ACP); decisionmaking

Submitted Oct 04, 2021. Accepted for publication Dec 29, 2021.

doi: 10.21037/apm-21-2854

View this article at: https://dx.doi.org/10.21037/apm-21-2854

^ ORCID: 0000-0003-2613-0957. 


\section{Introduction}

Despite continuous improvements in the past decades, and although mortality rates vary significantly according to the type of tumor, cancer remains one of the leading causes of death worldwide (1). Acute life-threatening situations are often difficult to anticipate in cancer patients. In such cases, cardiopulmonary resuscitation remains the default treatment, unless there is a documented decision to the contrary (2).

Faced with emergencies, uncertainty about the effectiveness of resuscitation and the traumatic emotional context, decision making may be difficult for physicians, especially for oncologists and Intensive Care Unit (ICU) physicians. It is noteworthy that a lack of advance care planning (ACP) often leads to unwarranted ICU transfers and excessive emergency admissions, and it may result in unsatisfactory communication between caregivers and poor information transfer to patients and their families (3). Conversely, early discussions about end-of-life (EOL), goals of care (GOC) and ACP are associated with improved patient and family outcomes, including better quality of life, reduced use of non-beneficial medical care near death, and treatment that is more consistent with patients' goals (4-8).

Best practice clinical end-of-life documents or decision supports for resuscitation situations have been previously reported (9-13). However, most of these tools have been created in an English-speaking setting, and France still lags behind other countries regarding anticipated approaches to end-of-life care such as ACP and EOL discussions. Therefore, as a part of a major institutional program to integrate oncology with palliative care, in 2015 a multidisciplinary group began using a "Decision-Aid Form" (DAF, Figure 1), which contains an outline of the expected stratification-of-care for patients hospitalized at our center. In order to build the DAF, a Delphi method was used, and a consensus was finally achieved among the focus group. Since the implementation in the hospital, this document is now routinely completed by physicians at each hospitalization, and it aims to encourage multidisciplinary thinking, to facilitate the documentation of care stratification and to ensure that the information given to the patients and their families is suitably transferred.

In our study, we present an assessment of this practical tool, which is now being implemented in routine practice and we focus on (I) the quality of the information recorded and (II) the predictive value of the stratification of care on patients' outcomes.

\section{Methods}

\section{Study design}

This prospective cohort study was conducted over a 5-month period in France's Gustave Roussy Cancer Center, located in two sites: GR1, the main site where treatment is provided and the second one, GR2, a follow-up care and rehabilitation unit. All adult patients who were transferred from GR1 to GR2 during the study period were included, at the time of first admission. For every individual patient, a physician completed a DAF which was then transmitted by fax to the GR2 medical unit. Until their discharge from the hospital, patients were followed-up for the occurrence of acute medical events, as recorded on the electronic charts, and then up to 6 months for long-term outcomes. About 200 patients were expected to be included over the recruitment period. This number allows a precision of at least 7 percentage points for estimates of proportions.

\section{Objectives}

The main goal of this study was to assess the acceptability and the degree of completeness of the DAF in daily practice. Additional aims were to assess (I) the prognostic value of the proposed stratification on the actual level of care delivered in the subset of patients with an acute event; (II) the correlation between stratification of care and outcome in the overall population.

\section{Focus group}

The multidisciplinary team was composed of fifteen caregivers from medical and surgical departments, of which seven were oncology, intensive care, and palliative care physicians. The members answered repetitive questionnaires (a Delphi method was used for the two first rounds), and five meetings of the focus group were organized. Finally, a consensus was obtained among the "experts". The DAF was first tested in patients who were transferred from the main site of our hospital to the second one, a follow-up care unit. Then, the DAF was tested in three additional oncology units, before a general implementation in the hospital.

\section{Description of the DAF}

The DAF contains four fields (Figure 1). The first section records the circumstances under which the form was completed (date, caregivers involved, whether or not 


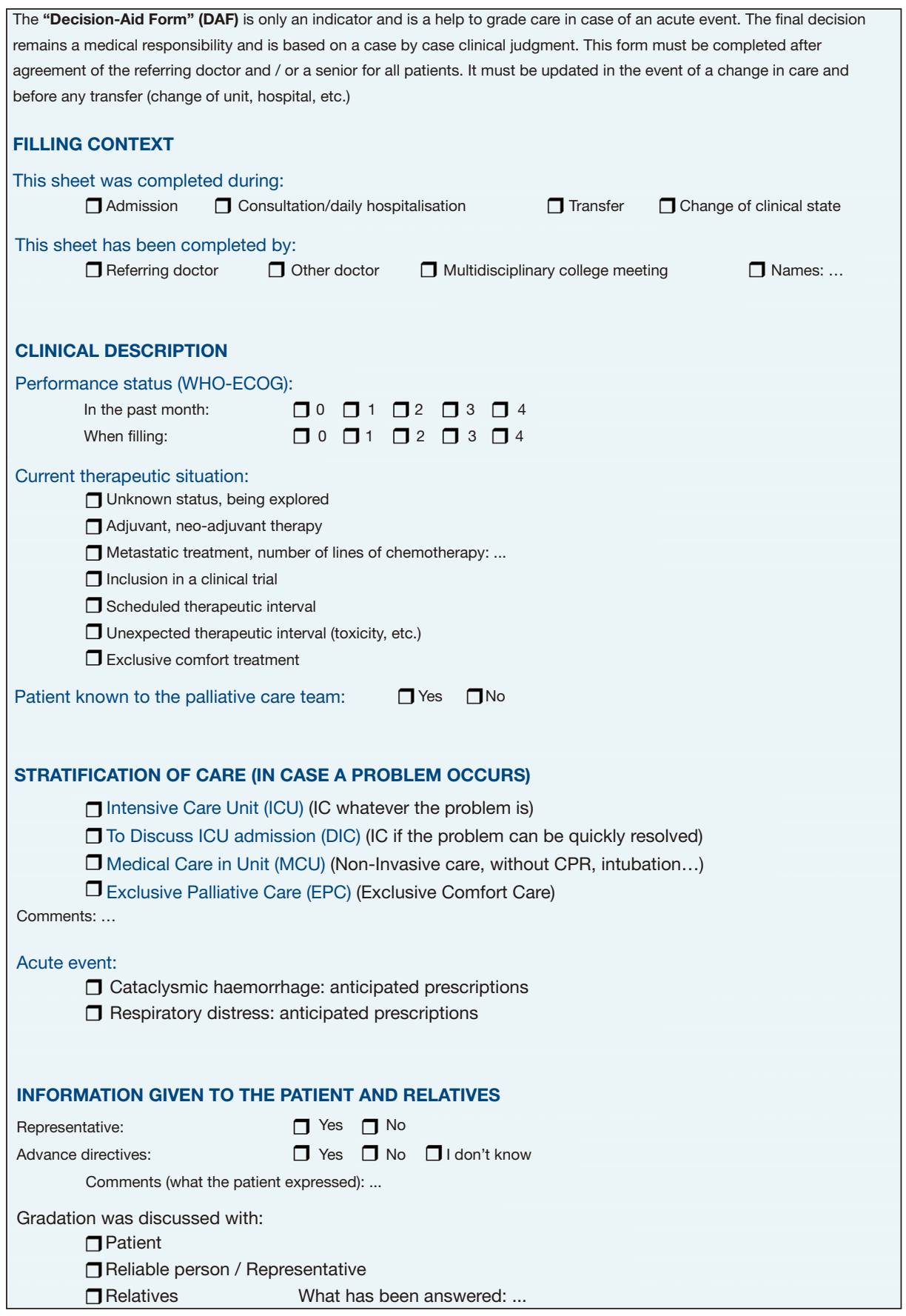

Figure 1 Decision-Aid Form.

medical staff meetings were held, etc.). The second part describes the patient's clinical status: therapeutic engagement, involvement of the interdisciplinary palliative care team (IPCT) and ECOG Performance Status (PS) during the previous month (in addition to the DAF, the
PS was recorded immediately before and after transfer). In the third field, four degrees of planned stratification of care are proposed in case of an acute event: "Intensive Care" ICU (Intensive care whatever the problem), "To Discuss Intensive Care Admission" DIC (Intensive care if the problem 


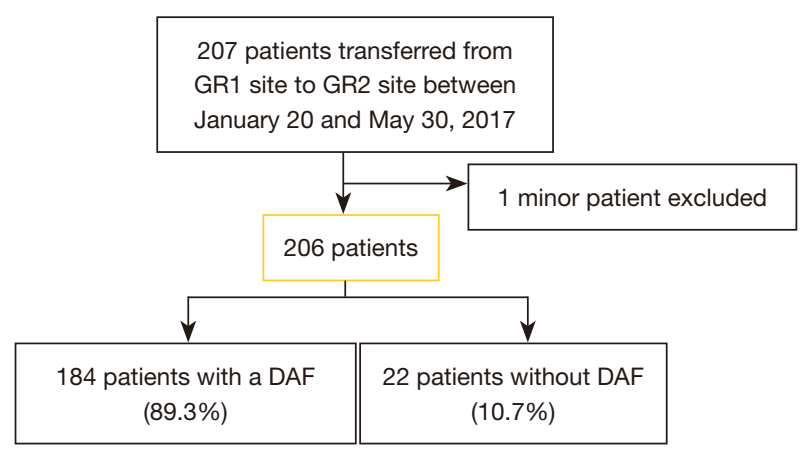

Figure 2 Number of patients included and presence of a DAF. DAF, Decision-Aid Form.

can be quickly resolved), "Medical Care in Unit" MCU (Non-invasive care, without cardiopulmonary resuscitation), "Exclusive Palliative Care" EPC (Exclusive comfort care). In addition, two specific "at risk situations" are identified: acute respiratory distress and acute hemorrhage, leading to possible anticipated interventions. The fourth field is dedicated to the information given to patients and relatives about possible worsening and of the level of care stratification.

\section{Data collection}

A complete list of all adult patients transferred from GR1 to GR2 during the study period was obtained thanks to the hospital's medical data information system. The Clinical Research Associate (CRA) collected the medical data retrieved from the hospital computer data base at patient discharge, and then for 6 months. Twice a week, the CRA examined each chart for possible acute events. Guidelines for the diagnosis of complications were provided, and a clinical validation was performed retrospectively by two physicians for each event collected. Data collection was performed in a standardized and anonymous manner, using REDCap electronic data capture tools hosted at Gustave Roussy cancer center (14), by the CRA. Quality controls during data entry were implemented.

\section{Statistical analysis}

Analyses were performed on all included adult patients. According to described variables, subgroup analyses were implemented on patients with filled-in DAF or patients with acute events.

Quantitative data were summarized using number of observations and quartiles [median and interquartile range (IQR)]. Qualitative data were summarized using number of observations and proportion by modality. Missing data were described.

The acceptability of the DAF in daily practice was assessed by the number of filled-in forms and items. The prognostic value of the proposed stratification provided by the DAF on the actual level of care delivered was described. Then, the prognostic value of the proposed stratification and of WHO-ECOG PS on patient outcomes was assessed by graphical representation of overall survival curves estimated with Kaplan-Meier. Stratification over the criteria of interest (level of care, ECOG PS), when filledin, was completed with log-rank test for equality of survival (considered exploratory $\alpha$-level of $5 \%$ ).

All statistical analyses were performed using SAS 9.4 software.

\section{Ethical statement}

The study was conducted in accordance with the Declaration of Helsinki (as revised in 2013). The study was approved by the Institutional Ethics Committee (No. 94805) and by the Institutional Scientific Review Board of Gustave Roussy Hospital, and given the strictly non-interventional design of the study (analysis of data usually recorded for all hospitalized patients), informed consent for this analysis was waived by the Institutional Ethics Committee of Gustave Roussy Hospital (approval No. 2016-12-03).

\section{Results}

Between January 20th and May 30th, 2017, 207 patients were transferred (median, 63 years). One minor patient was excluded from the analysis. Of these 206 adult patients, 184 (89.3\%) had a DAF (Figure 2). The patients were mainly transferred from the medical oncology unit (54\%), 20\% were transferred from the emergency room, less than $10 \%$ from the hematology unit; surgical patients accounted for less than $20 \%$ of our population (of which one half came from the head and neck department).

\section{Quality of data recorded and characteristics of the patients (Table 1)}

The first section (circumstances of recording) was completed in more than $90 \%$ of the $184 \mathrm{DAF}$, but in a 
Table 1 Quality of fulfilling of the four fields of the Decision-Aid Form (DAF)

\begin{tabular}{|c|c|c|}
\hline DAF analysed & $\mathrm{N}=184$ & $\%$ \\
\hline \multicolumn{3}{|l|}{ FIELD \#1 } \\
\hline Date mentioned & 179 & 97.3 \\
\hline Identification of caregivers & 170 & 92.4 \\
\hline Referring oncologist & 54 & 29.3 \\
\hline Other physician & 106 & 57.6 \\
\hline Not mentioned & 14 & 7.6 \\
\hline Collegial instance & 10 & 5.5 \\
\hline With the referring oncologist & 6 & 60 \\
\hline With a senior physician & 8 & 80 \\
\hline With the palliative care specialist & 3 & 30 \\
\hline With the resident & 7 & 70 \\
\hline With the nursing staff & 0 & 0 \\
\hline \multicolumn{3}{|l|}{ FIELD \#2 } \\
\hline WHO/ECOG performance status & 165 & 89.7 \\
\hline 1 & 57 & 31 \\
\hline 2 & 73 & 39.7 \\
\hline 3 & 30 & 16.3 \\
\hline 4 & 5 & 2.7 \\
\hline WHO/ECOG performance Not mentioned & 19 & 10.3 \\
\hline Therapeutic engagement & 170 & 92.4 \\
\hline $\begin{array}{l}\text { Involvement of the interdisciplinary } \\
\text { palliative care team }\end{array}$ & 53 & 28.8 \\
\hline Yes & 12 & 6.5 \\
\hline No & 41 & 22.3 \\
\hline Not mentioned & 131 & 71.2 \\
\hline \multicolumn{3}{|l|}{ FIELD \#3 } \\
\hline $\begin{array}{l}\text { Planned gradation of care in case of acute } \\
\text { event }\end{array}$ & 179 & 97.3 \\
\hline Intensive care whatever the problem & 61 & 33.15 \\
\hline Discuss intensive care & 57 & 31 \\
\hline Maximal care in unit, without CPR & 59 & 32.1 \\
\hline Exclusive comfort care & 2 & 1.1 \\
\hline Not mentioned & 5 & 2.7 \\
\hline
\end{tabular}

Table 1 (continued)
Table 1 (continued)

\begin{tabular}{|c|c|c|}
\hline DAF analysed & $\mathrm{N}=184$ & $\%$ \\
\hline \multicolumn{3}{|l|}{ "At risk situations" identified } \\
\hline Acute haemorrhage $^{\star}$ & 1 & 0.5 \\
\hline Anticipated prescriptions & 1 & \\
\hline Acute respiratory distress ${ }^{\star *}$ & 2 & 1.1 \\
\hline Anticipated prescriptions ${ }^{\star \star \star}$ & 1 & \\
\hline \multicolumn{3}{|l|}{ FIELD \#4 } \\
\hline \multicolumn{3}{|l|}{ Information of patients and proxies } \\
\hline Yes & 12 & 6.52 \\
\hline With the patient & 9 & 75 \\
\hline With the representative & 4 & 33.3 \\
\hline With relatives & 1 & 8.3 \\
\hline No & 14 & 7.6 \\
\hline Not mentioned & 158 & 85.9 \\
\hline \multicolumn{3}{|l|}{ Are there advance directives? } \\
\hline Yes & 1 & 0.5 \\
\hline No & 12 & 6.5 \\
\hline Not mentioned & 171 & 92.9 \\
\hline \multicolumn{3}{|c|}{$\begin{array}{l}\text { *, one patient was noted as at risk for cataclysmic haemorrhage } \\
\text { the decision was noted as "not discussed with the patient } \\
\text { or relatives". The gradation was "Intensive care whatever } \\
\text { the problem". The patient did not present the event during } \\
\text { hospitalization at Site } 2 .{ }^{* \star} \text {, two patients were notified "at risk of } \\
\text { acute respiratory distress": the decision was discussed with the } \\
\text { patient or relatives for both. The gradation was "Maximal care in } \\
\text { unit" for one and "Exclusive comfort care" for the other patient } \\
\text { None of the patients presented the event during hospitalization } \\
* * * \text {, recommendation of tracheotomy and anticipateo } \\
\text { prescriptions were made. }\end{array}$} \\
\hline
\end{tabular}

multidisciplinary setting in only $5.5 \%$. The form was often completed by a single physician, usually a resident. A member of the nursing staff or the referring oncologist were only rarely involved (in less than one third of the cases, the physician was a referring oncologist). The second part (clinical status) was widely completed, except the involvement of the IPCT, which was checked in less than $30 \%$ of the cases (and in fact involved only $6.5 \%$ of patients). Most of the patients had a PS (assessed during the previous month) lower than 3 . The planned stratification 
Table 2 Characteristics of acute events occurring during the hospitalization

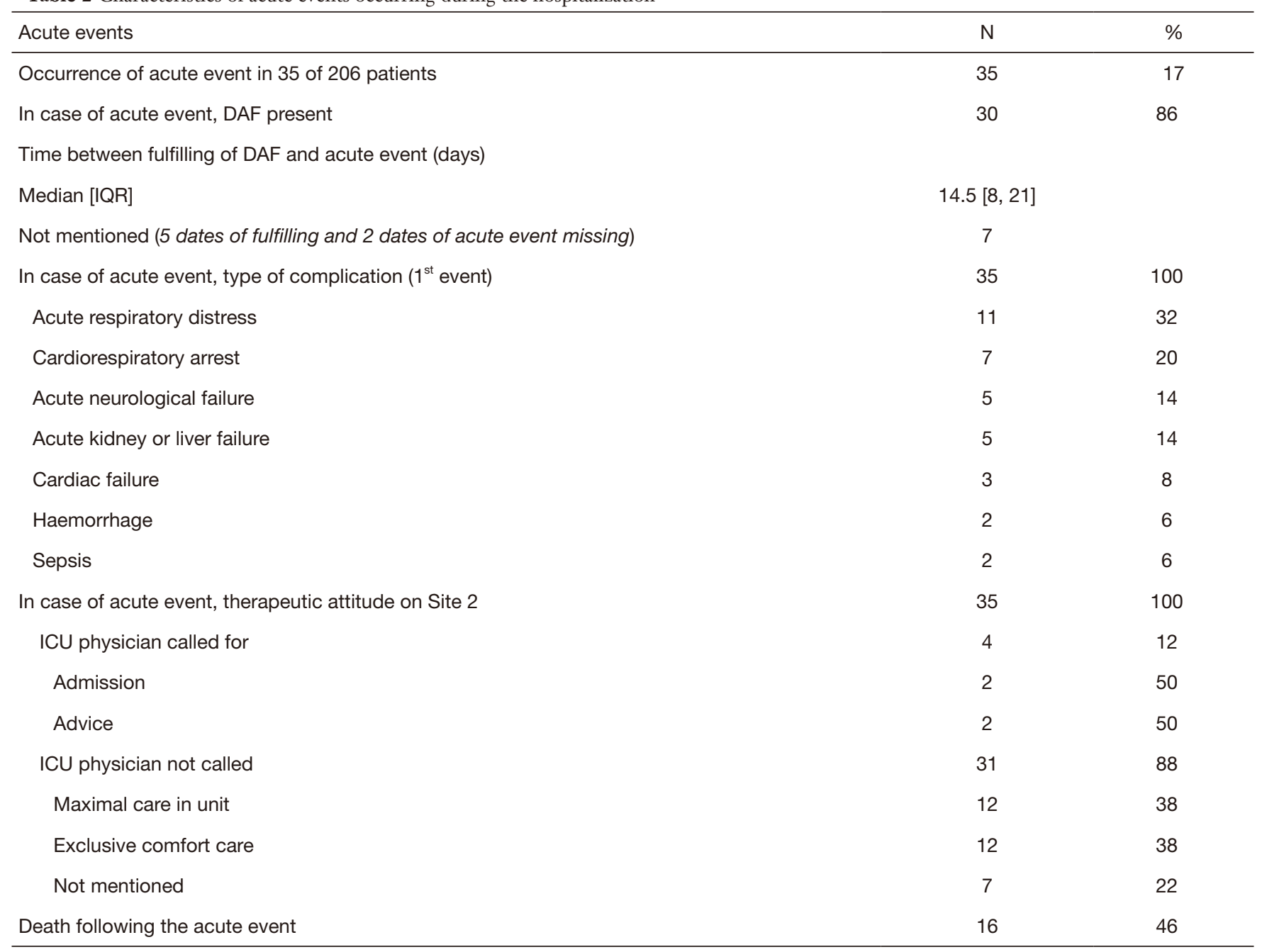

DAF, Decision-Aid Form; ICU, Intensive Care Unit; IQR, interquartile range.

of care $\left(3^{\text {rd }}\right.$ field) was indicated in almost all cases, leading to proposed intensive care in $64 \%$ of patients; conversely, "at risk situations" were rarely identified. Finally, the fourth field (information) was rarely completed; overall, the stratification of care was explained in only $6.5 \%$ of cases, primarily to the patients themselves.

\section{Acute medical events and therapeutic decisions}

For the 206 included patients, the median duration of stay in GR2 was 22 days; 35 (17\%) experienced an acute event after a median of 2 weeks (Table 2), of whom 30 had a DAF. Acute dyspnea and cardiorespiratory arrest accounted for $50 \%$ of cases. These events resulted in a resuscitation call only four times. Three-quarters of acute events were treated equally by $M C U$ and $E P C$. Overall, 16 of the 35 acute events led to death.

\section{Stratification of care, acute events and therapeutic decisions}

Of the 30 patients with a DAF who had an acute event (Figure 3), only one patient had no stratification recommendation: this patient received palliative care and later died. For 7 of the other 29 patients, the chart did not indicate a clear attitude facing an acute event: in their DAF, two patients had a DIC order, 5 had a $M C U$ order; 3 of whom died.

Among the 22 remaining patients, the approach remained at or below the expected graduation level of the DAF for a vast majority of patients. Seven patients were 


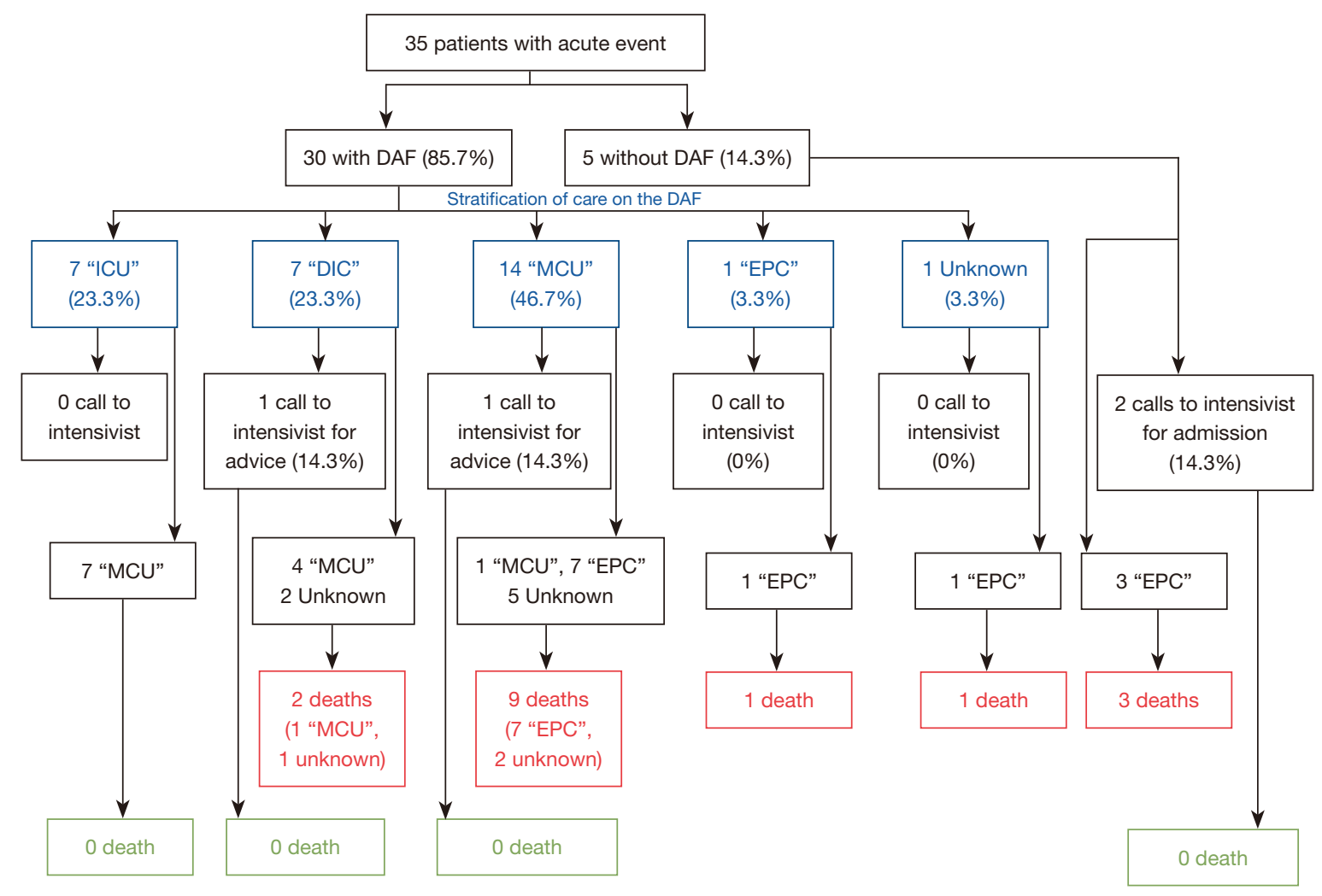

Figure 3 Gradation of care and evolution in the 35 patients with an acute complication. ICU, Intensive Care Unit; DIC, To Discuss Intensive Care Admission; MCU, Medical Care in Unit; EPC, Exclusive Palliative Care; DAF, Decision-Aid Form.

marked $I C U$ : all received $M C U$ without contacting the intensivist, improved rapidly and survived. Of the 7 patients with $D I C$ order, all received non-invasive medical care: the intensivist was contacted only once, with a favorable evolution without transfer, while 2 of the 6 other patients died. Of the 14 patients considered $M C U, 50 \%$ received palliative care; only once was the intensivist contacted for advice and the patient survived. Finally, the only patient labeled $E P C$ in fact received palliative care and later died.

The 12 cases where stratification was discussed with the patient and/or relatives were examined more closely; details are given in the Supplementary file (Appendix 1).

\section{Correlation between stratification of care and outcome}

A total of 108 of the 206 patients died within 6 months: 20 in hospital, 88 after hospital discharge, including 35 during the month following discharge. Among patients with documented stratification of care, 6-month mortality rates were respectively $23 \%, 58 \%$ and $72 \%$ for ICU, DIC and $M C U$ or EPC patients. As shown by Kaplan-Meier survival curves of the 179 patients for whom the stratification of care was well recorded in the DAF (Figure 4), death rates increased according to the level of stratification of care, from ICU to $E P C$ (Log-rank test, $\mathrm{P}<0.0001)$.

\section{ECOG PS}

The ECOG PS was recorded in the DAF (reflecting the clinical status during the previous month) and immediately before and after transfer. Detailed data are given in the Supplementary file (Appendix 1). Briefly, the two assessments at GR1 were correlated and did not appear to predict long-term survival (Table S1, Figure 5). They differed significantly from the PS assessed at GR2, which was, in fact, predictive of long-term survival (Table S2, Figure 6).

\section{Discussion}

In oncology, several international studies have shown both feasibility and interest in an early stratification of 


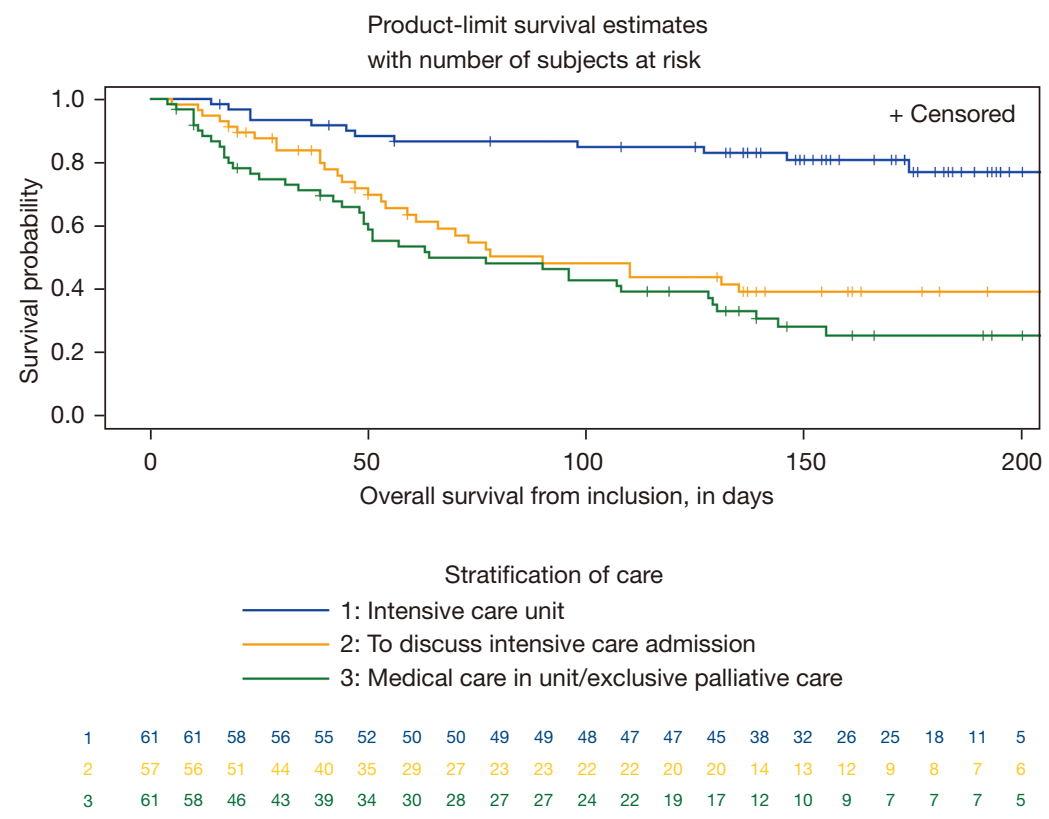

Figure 4 Six-month survival curves according to the level of stratification of care (when recorded in the Decision-Aid Form, N=179).

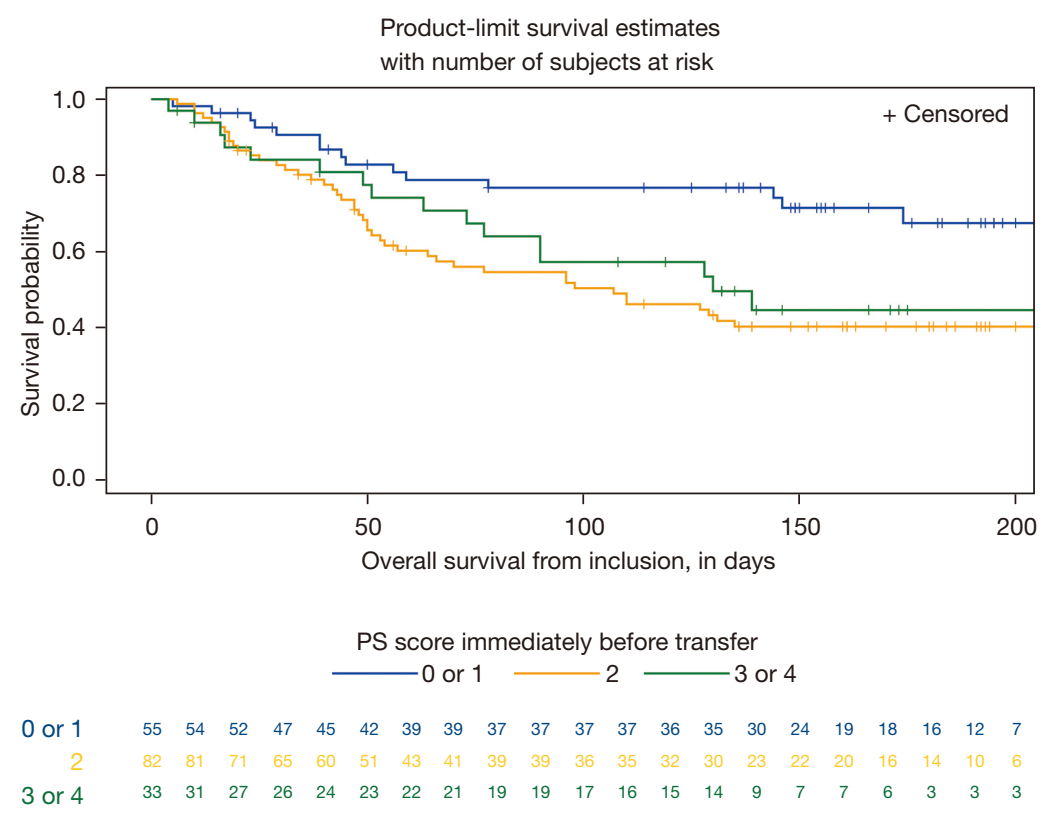

Figure 5 Six-month survival curves according to the WHO-ECOG Performance Status immediately before transfer from Gustave Roussy Site 1 to Gustave Roussy Site $2(\mathrm{~N}=170)$.

therapeutic commitment, should a patient's condition worsen and in compliance with their preferences (10-13). The present study not only shows the feasibility of such an anticipated approach in a French oncology setting and a positive effect on the aggressiveness of care, but also identifies some limits in terms of completion, utilization and sharing of information/decisions with patients and relatives.

In our hospital, a major institutional program was designed in 2015 to improve the integration of oncology and palliative care, as recommended by numerous experts 


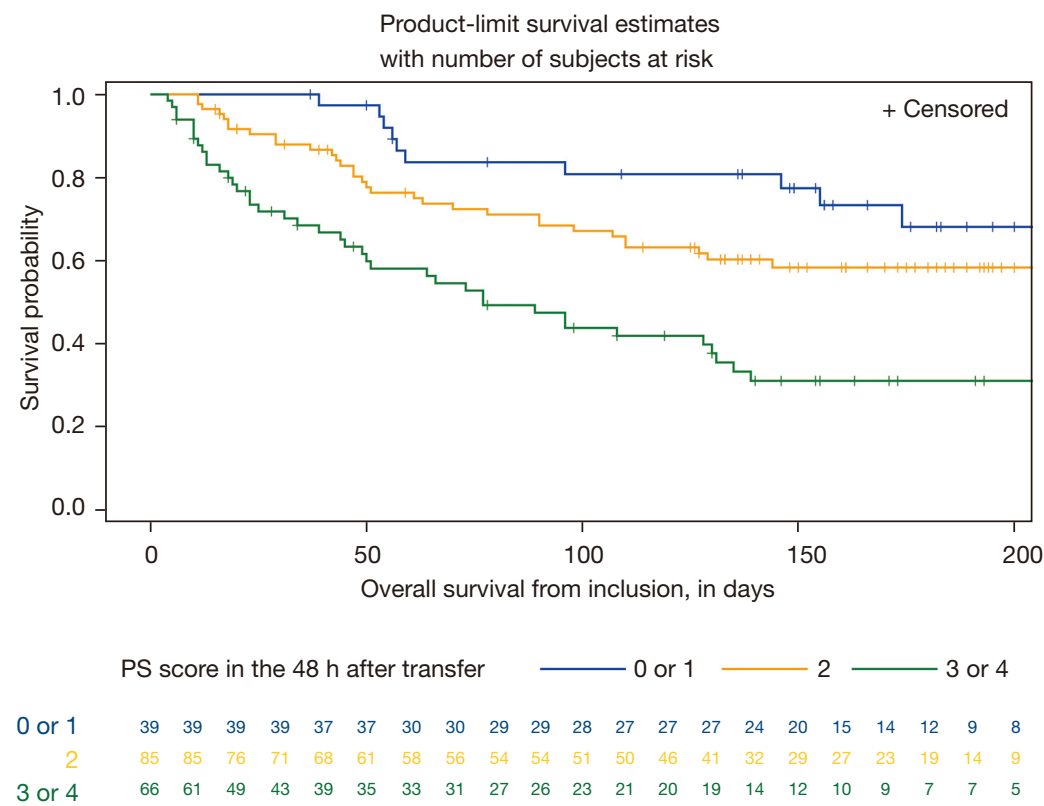

Figure 6 Six-month survival curves according to the WHO-ECOG Performance Status immediately after admission to Gustave Roussy Site $2(\mathrm{~N}=190)$.

(15-19). As part of this program, the DAF was designed by a multidisciplinary group which included medical and paramedical professionals in medical oncology, surgical, palliative and intensive care teams. The multidisciplinary development of the DAF permitted its rapid and wide acceptance in the units.

Our initiative was encouraged by numerous experiences worldwide and an extensive literature. Indeed, anticipating approaches such as do-not-resuscitate (DNR) orders, early palliative care, ACP and end-of-life discussions have been shown to reduce inappropriate use of aggressive treatments such as ICU transfers or emergency admissions (3-13). Among EOL documents or decision supports for resuscitation situations (9-13), the Universal Form of Treatment Option (UFTO) is an original tool which has been demonstrated to improve patient care and reduce aggressiveness of care $(10,11)$. This tool differs from classical DNR orders in so far as it first documents clinical conditions, clarify goals of overall treatment (active treatment or optimal supportive care) and records the wishes of the patients and their families. That was also our choice to develop a new tool emphasizing the clinical context and encouraging to share treatment objectives and medical discussions with patients and relatives.

As suggested by our results, the DAF was widely and quickly accepted in our hospital, and the ultimate aim to reduce the aggressiveness of care by anticipating the risk of acute events was, at least partially, reached. However, we were concerned by several limitations in using this tool, first of all destined to improve the anticipation culture in cancer setting. The fact that some crucial items were not frequently filled-in (Table 1) is probably the main symptom of these limitations. First, the form was most often completed by a single physician, indicating a lack of collegiality in many cases. Indeed, a larger involvement of the nursing staff and of the referring oncologist would improve both the estimation of prognosis and stratification of care. Recently published DAFs such as the Physician Orders for Life-Sustaining Treatment (POLST) and the UFTO enlarge the decisional circle by including patients' values and preferences $(10,13)$, as discussed below for the $4^{\text {th }}$ field of the DAF.

The second field (clinical status) showed an uncommon involvement of the palliative care team. Clearly, this is a troubling finding when considering the high number of patients assessed as $M C U$ or $E P C$, as well as the numerous deaths within the following months (Figure 4). This contrasts with findings of a wider literature and international recommendations about the importance of early palliative care in patients with advanced or metastatic cancer (14-22). Palliative care, when combined with standard cancer care, leads to better patient and caregiver outcomes. These include improvement in symptoms, 
quality of life, and patient satisfaction, with reduced caregiver burden. Earlier involvement of palliative care also leads to more appropriate referral to and use of hospice, and reduces use of futile intensive care (21).

Finally, the gaps in the last field showed that this information was rarely delivered/shared with patients and relatives, and that the search for advance directives was rarely performed (9). This finding underlines the noteworthy difficulty of sharing a clear definition of the GOC with patients and/or having EOL discussions with them. Yet, EOL discussions are associated with less aggressive medical care near death and earlier hospice referrals $(5,23)$. However, conversations regarding GOC with patients who have advanced cancer still occur too late and less than half of cancer patients benefit from such discussions (23-25).

Therefore, these findings are not only a practical limitation to optimal use of the DAF, but especially to ethical concerns. These partly arise from cultural difficulties in France regarding the sharing of information about GOC and EOL discussions, as well as reporting of palliative care needs (26).

Another finding was the limited value of the ECOGPS both in the DAF and immediately before transfer, as regards the assessment of the patient's general condition. Survival curves were more in agreement with the estimated PS at the arrival in the second unit, than with the scores evaluated on the DAF or immediately before transfer. This difference between site 1 and site 2 is probably explained by a more objective judgment of the site 2 team, only based on the actual PS and not on cancer prognosis or other subjective criteria. The ECOG-PS is a unidimensional score subjectively assessed and therefore open to bias, as previously reported (27). For example, physician ECOGPS ratings seem less predictive of outcome than those of nurses, and a disagreement between physician and nurse ECOG-PS rating is in itself predictive of poor prognosis when the physician give healthier (lower) scores (28). Therefore, more objective scores would be suitable to describe the patient's current general condition, such as the Clinical Frailty Score (29), functional measures of physical performance (30) or the Barbot's score (31).

Despite the numerous limitations mentioned above, an encouraging finding in our series is that anticipation allowed by a decision-aid tool could contribute to reduce the aggressiveness of care, as shown in POLST shared with patients (32). Thus, whenever complications arose, the level of therapeutic commitment indicated in the DAF was either respected or "revised downwards". Interpretations of this partial fit (toward less intervention) between actual decisions and DAF proposals are multiple. First, the clinical situation may have changed, and a worsening may have led to reconsidering the commitment to less aggressive treatment. Second, before transferring the patient to another unit, the clinician drafting the DAF might have opted to follow a high "precautionary principle" (advocating use of resuscitation, to avoid "loss of opportunity"); conversely, the person evaluating the patient in the reception unit and examining them later during an acute event, more often preferred to limit the intensity of care. The marked difference of PS evaluation after transfer, compared to that immediately before transfer (Tables S1,S2, additional supporting information), and the survival curves (Figures 5,6) suggest that clinical evaluation was more reliable at the time of arrival, possibly leading to better therapeutic choices. In fact, the initial stratification in the DAF seems more related to the general prognosis, regardless of whether or not an acute event occurs. Figure 4 shows a clearly different evolution between patients assessed as ICU and others: patients with a $D I C$ proposal have a prognosis close to $M C U$ or $E P C$ patients. This probably reflects a more or less conscious "moderation" of the prognostic evaluation for such patients, and a poorly defined limit between DIC and $M C U$ status. Finally, these findings indicate not only those therapeutic commitments must be respected, but also that changes in the clinical situation may prompt clinicians to revise this commitment towards less aggressive strategies.

This study has several limitations. The observational and slightly delayed nature of the collection of acute data probably biases the completeness precision of the observations; the absence of DAF for some patients did not permit an exhaustive study of clinical situations; the number of cases forecast in the design of the study reflects only approximately 5 months of care. In contrast, several strengths should be noted: transferred patients were prospectively identified and consecutively included; collection of data and analysis methodology were homogeneous; transferred patients came from a wide variety of units; short and longterm analyses (up to 6 months) were performed.

\section{Conclusions}

The present study shows that the implementation of an advance stratification record is possible in a French cultural setting. The finding that the suggested level of therapeutic commitment was never upgraded (and often revised towards 
less aggressive care) encourages us to pursue our efforts toward a greater implementation of ACP in our institution.

Nevertheless, several concerns regarding acceptance of cultural change remain, such as the lack of collegiality, insufficient involvement of the palliative care team, and finally a sharing of information and decisions that are only partially made. Therefore, our major integrative institutional program can be considered a first step towards improving the planning for unanticipated events, documentation and consistent sharing of information with patients and relatives.

\section{Acknowledgments}

The authors warmly thank Richard Medeiros, Medical Editor-Medical Editing International, Mr. Fred Sengmueller and Dr. Edward L. Lilly (Norfolk, VA) for editing the final version of the manuscript, as well as Ms. Ellen Benhamou for his help in designing this study.

Funding: This study was funded by an IFAQ grant (Financial Incentive for Quality improvement, No. IFAQ.2015-05/11), from the French National Authority for Health (HAS) and the Direction Générale de l'Offre de Soins (DGOS).

\section{Footnote}

Data Sharing Statement: Available at https://apm.amegroups. com/article/view/10.21037/apm-21-2854/dss

Peer Review File: Available at https://apm.amegroups.com/ article/view/10.21037/apm-21-2854/prf

Conflicts of Interest: All authors have completed the ICMJE uniform disclosure form (available at https://apm. amegroups.com/article/view/10.21037/apm-21-2854/coif). FB and SD report that the study was funded by an IFAQ grant (Financial Incentive for Quality improvement, No. IFAQ.2015-05/11), from the French National Authority for Health (Haute Autorité de Santé, HAS) and the General Direction of Healthcare (Direction Générale de l'Offre de Soins, DGOS). The other authors have no conflicts of interest to declare.

Ethical Statement: The authors are accountable for all aspects of the work in ensuring that questions related to the accuracy or integrity of any part of the work are appropriately investigated and resolved. The study was conducted in accordance with the Declaration of Helsinki (as revised in 2013). The study was approved by the Institutional Ethics Committee (No. 94805) and by the Institutional Scientific Review Board of Gustave Roussy Hospital, and given the strictly non-interventional design of the study (analysis of data usually recorded for all hospitalized patients), informed consent for this analysis was waived by the Institutional Ethics Committee of Gustave Roussy Hospital (approval No. 2016-12-03).

Open Access Statement: This is an Open Access article distributed in accordance with the Creative Commons Attribution-NonCommercial-NoDerivs 4.0 International License (CC BY-NC-ND 4.0), which permits the noncommercial replication and distribution of the article with the strict proviso that no changes or edits are made and the original work is properly cited (including links to both the formal publication through the relevant DOI and the license). See: https://creativecommons.org/licenses/by-nc-nd/4.0/.

\section{References}

1. Sung H, Ferlay J, Siegel RL, et al. Global Cancer Statistics 2020: GLOBOCAN Estimates of Incidence and Mortality Worldwide for 36 Cancers in 185 Countries. CA Cancer J Clin 2021;71:209-49.

2. Levinson M, Mills A. Cardiopulmonary resuscitation--time for a change in the paradigm? Med J Aust 2014;201:152-4.

3. Barnato AE, Mohan D, Lane RK, et al. Advance care planning norms may contribute to hospital variation in end-of-life ICU use: a simulation study. Med Decis Making 2014;34:473-84.

4. Mack JW, Smith TJ. Reasons why physicians do not have discussions about poor prognosis, why it matters, and what can be improved. J Clin Oncol 2012;30:2715-7.

5. Bernacki RE, Block SD; American College of Physicians High Value Care Task Force. Communication about serious illness care goals: a review and synthesis of best practices. JAMA Intern Med 2014;174:1994-2003.

6. Dans M, Smith T, Back A, et al. NCCN Guidelines Insights: Palliative Care, Version 2.2017. J Natl Compr Canc Netw 2017;15:989-97.

7. Rietjens JAC, Sudore RL, Connolly M, et al. Definition and recommendations for advance care planning: an international consensus supported by the European Association for Palliative Care. Lancet Oncol 2017;18:e543-51.

8. The Lancet. Why talking about dying matters. Lancet 2018;392:1488. 
9. Obolensky L, Clark T, Matthew G, et al. A patient and relative centred evaluation of treatment escalation plans: a replacement for the do-not-resuscitate process. J Med Ethics 2010;36:518-20.

10. Fritz Z, Malyon A, Frankau JM, et al. The Universal Form of Treatment Options (UFTO) as an alternative to Do Not Attempt Cardiopulmonary Resuscitation (DNACPR) orders: a mixed methods evaluation of the effects on clinical practice and patient care. PLoS One 2013;8:e70977.

11. Fritz Z, Fuld JP. Development of the Universal Form Of Treatment Options (UFTO) as an alternative to Do Not Attempt Cardiopulmonary Resuscitation (DNACPR) orders: a cross-disciplinary approach. J Eval Clin Pract 2015;21:109-17.

12. Lammers AJ, Zive DM, Tolle SW, et al. The Oncology Specialist's Role in POLST Form Completion. Am J Hosp Palliat Care 2018;35:297-303.

13. Nugent SM, Slatore CG, Ganzini L, et al. POLST Registration and Associated Outcomes Among Veterans With Advanced-Stage Lung Cancer. Am J Hosp Palliat Care 2019;36:564-70.

14. Harris PA, Taylor R, Minor BL, et al. The REDCap consortium: Building an international community of software platform partners. J Biomed Inform 2019;95:103208.

15. Temel JS, Greer JA, Muzikansky A, et al. Early palliative care for patients with metastatic non-small-cell lung cancer. N Engl J Med 2010;363:733-42.

16. Yoong J, Park ER, Greer JA, et al. Early palliative care in advanced lung cancer: a qualitative study. JAMA Intern Med 2013;173:283-90.

17. Hui D, Bruera E. Models of integration of oncology and palliative care. Ann Palliat Med 2015;4:89-98.

18. Temel JS, Greer JA, El-Jawahri A, et al. Effects of Early Integrated Palliative Care in Patients With Lung and GI Cancer: A Randomized Clinical Trial. J Clin Oncol 2017;35:834-41.

19. Courteau C, Chaput G, Musgrave L, et al. Patients with advanced cancer: when, why, and how to refer to palliative care services. Curr Oncol 2018;25:403-8.

20. Bakitas M, Lyons KD, Hegel MT, et al. Effects of a palliative care intervention on clinical outcomes in patients with advanced cancer: the Project ENABLE II randomized controlled trial. JAMA 2009;302:741-9.

21. Smith TJ, Temin S, Alesi ER, et al. American Society of Clinical Oncology provisional clinical opinion: the integration of palliative care into standard oncology care. J
Clin Oncol 2012;30:880-7.

22. Bakitas MA, Tosteson TD, Li Z, et al. Early Versus Delayed Initiation of Concurrent Palliative Oncology Care: Patient Outcomes in the ENABLE III Randomized Controlled Trial. J Clin Oncol 2015;33:1438-45.

23. Wright AA, Zhang B, Ray A, et al. Associations between end-of-life discussions, patient mental health, medical care near death, and caregiver bereavement adjustment. JAMA 2008;300:1665-73.

24. Jain N, Bernacki RE. Goals of Care Conversations in Serious Illness: A Practical Guide. Med Clin North Am 2020;104:375-89.

25. Childers JW, Back AL, Tulsky JA, et al. REMAP: A Framework for Goals of Care Conversations. J Oncol Pract 2017;13:e844-50.

26. Goldwasser F, Vinant P, Aubry R, et al. Timing of palliative care needs reporting and aggressiveness of care near the end of life in metastatic lung cancer: A national registrybased study. Cancer 2018;124:3044-51.

27. Sok M, Zavrl M, Greif B, et al. Objective assessment of WHO/ECOG performance status. Support Care Cancer 2019;27:3793-8.

28. Neeman E, Gresham G, Ovasapians N, et al. Comparing Physician and Nurse Eastern Cooperative Oncology Group Performance Status (ECOG-PS) Ratings as Predictors of Clinical Outcomes in Patients with Cancer. Oncologist 2019;24:e1460-6.

29. Simcock R, Wright J. Beyond Performance Status. Clin Oncol (R Coll Radiol) 2020;32:553-61.

30. Quinn SE, Crandell CE, Blake ME, et al. The Correlative Strength of Objective Physical Assessment Against the ECOG Performance Status Assessment in Individuals Diagnosed With Cancer. Phys Ther 2020;100:416-28.

31. Barbot AC, Mussault P, Ingrand P, et al. Assessing 2-month clinical prognosis in hospitalized patients with advanced solid tumors. J Clin Oncol 2008;26:2538-43.

32. Lee RY, Brumback LC, Sathitratanacheewin S, et al. Association of Physician Orders for Life-Sustaining Treatment With ICU Admission Among Patients Hospitalized Near the End of Life. JAMA 2020;323:950-60.

Cite this article as: Vigouret-Viant L, Legoupil C, Bardet A, Laurent C, Ducreux M, Laurent S, Mateus C, Dauchy S, Blot F. Development of a Decision-Aid Form (DAF) for the stratification of care in a French comprehensive cancer center, a tool to support identification of care goals. Ann Palliat Med 2022;11(6):1876-1887. doi: 10.21037/apm-21-2854 


\section{Supplementary}

\section{Table of contents:}

\section{List of investigators}

\section{Methods}

1. Stratification of care, acute events and therapeutic decisions

2. WHO/ECOG performance status (PS) on 3 evaluation times and outcome

Table S1 Comparison between WHO/ECOG performance status (PS) on the Aid to Decision-making Form and immediately before transfer

Table S2 Comparison between WHO/ECOG performance status (PS) immediately before and after transfer

\section{List of investigators (all authors):}

Laurence VIGOURET-VIANT MD ${ }^{1}$, Clémence LEGOUPIL $\mathrm{MD}^{2}$, Aurélie BARDET MSc ${ }^{2}$, Céline LAURENT ${ }^{3}$, Michel DUCREUX MD, $\mathrm{PhD}^{4}$, Sophie LAURENT MD ${ }^{1}$, Christine MATEUS MD ${ }^{1}$, Sarah DAUCHY MD ${ }^{1}$, François BLOT MD

Gustave Roussy, Paris-Saclay University, 1 Supportive Care Unit, Interdisciplinary Cancer Course Department, 2 Biostatistics and Epidemiology Department, 3 Clinical Research Associate, 4 Medical Oncology Department, 5 Intensive Care Unit, Villejuif, F-94800, France

\section{Methods}

\section{Stratification of care, acute events and therapeutic decisions}

The 12 cases where stratification was discussed with the patient and/or relatives were examined more closely: 3 were scored ICU, 3 DIC (discuss intensive care), $5 M C U$ (medical care in the unit) and 1 EPC (exclusive palliative care). An acute event occurred for 3 of them, all scored as $M C U$. There was no need for the resuscitator; case management was completed for only one patient who received exclusive palliative care and died. The other two patients were discharged from the hospital: one died 15 days later, the second patient was still alive at 6 months.

\section{WHO/ECOG performance status (PS) on 3 evaluation times and outcome}

Table S1 describes the WHO/ECOG PS as recorded in the DAF (reflecting the clinical status within the last month) and PS immediately before transfer, and shows a concordance of 78\% between the two assessments on GR1 (127 patients out of 162, green characters, Table S1). The PS recorded in the DAF was lower than the one before transfer in 12 cases (7\%), and higher in 23 cases (14\%). When compared to survival curves, pre-transfer PS scores [broadly close to DAF scores (Table S1)] did not appear to predict long-term survival (Figure 5): patients with a $\mathrm{PS}=2 \mathrm{had}$ a similar or even lower survival than patients classified PS >2 (Log-rank test, $\mathrm{P}=0.005)$.

Table S2 compares PS scores immediately before and after transfer on GR2, for the 156 patients whose data were completed; both estimates were 48 hours apart. Scores were consistent for $50 \%$ of the patients (77/156, green diagonal, Table S2). For 64 of the 156 patients (41\%), the pre-transfer PS was lower than at patient's admission, and greater in 15 (10\%). The PS scores within 48 hours after transfer, unlike the scores calculated on GR1 (i.e., before), were predictive of the long-term survival for the 190 patients for whom the item was completed (survival of patients assessed as PS 0-1 > PS $2>$ PS 3-4, Figure 6 . Log-rank test, $\mathrm{P}<0.0001)$. 
Table S1 Comparison between WHO/ECOG performance status (PS) on the to Decision-Aid Form and immediately before transfer

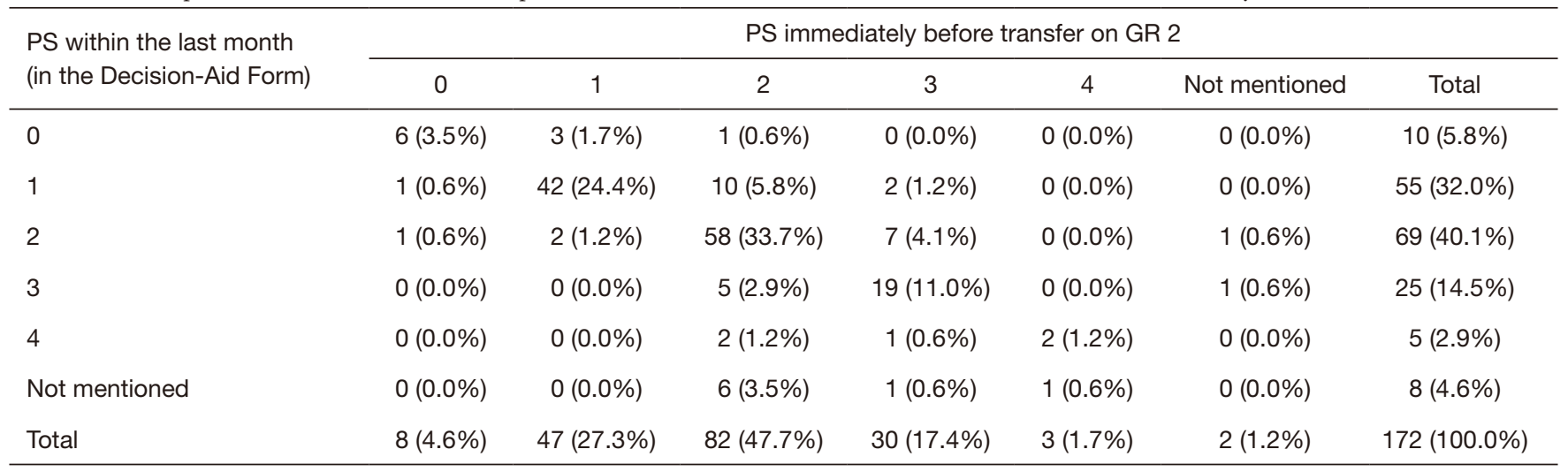

GR, Gustave Roussy site.

Table S2 Comparison between WHO/ECOG performance status (PS) immediately before and after transfer

\begin{tabular}{|c|c|c|c|c|c|c|}
\hline PS immediately before transfer on GR 2 & \multicolumn{6}{|c|}{ PS immediately within the first 48 hrs. on GR 2} \\
\hline 0 & $1(0.6 \%)$ & $4(2.5 \%)$ & $2(1.3 \%)$ & $0(0.0 \%)$ & $0(0.0 \%)$ & $7(4.4 \%)$ \\
\hline 1 & $0(0.0 \%)$ & $18(11.4 \%)$ & $18(11.4 \%)$ & $5(3.2 \%)$ & $1(0.6 \%)$ & $42(26.6 \%)$ \\
\hline 2 & $0(0.0 \%)$ & $5(3.2 \%)$ & $42(26.6 \%)$ & $27(17.1 \%)$ & $2(1.3 \%)$ & $76(48.1 \%)$ \\
\hline 4 & $0(0.0 \%)$ & $0(0.0 \%)$ & $0(0.0 \%)$ & $0(0.0 \%)$ & $3(1.9 \%)$ & $3(1.9 \%)$ \\
\hline Not mentioned & $0(0.0 \%)$ & $0(0.0 \%)$ & $2(1.3 \%)$ & $0(0.0 \%)$ & $0(0.0 \%)$ & $2(1.3 \%)$ \\
\hline Total & $1(0.6 \%)$ & $28(17.7 \%)$ & $73(46.2 \%)$ & $45(28.5 \%)$ & $11(7.0 \%)$ & $158(100.0 \%)$ \\
\hline
\end{tabular}

GR, Gustave Roussy site. 